\title{
Atomoxetine treatment in children and adolescents with attention- deficit hyperactivity disorder: what are the long-term health- related quality-of-life outcomes?
}

\author{
Amy R. Perwien \\ Eli Lilly \\ Christopher J. Kratochvil \\ University of Nebraska Medical Center, ckratoch@unmc.edu \\ Douglas E. Faries \\ Eli Lilly \\ Brigette S. Vaughan \\ University of Nebraska Medical Center, bvaughan@unmc.edu \\ Thomas Spencer \\ Harvard University \\ Tell us how you used this information in this short survey.

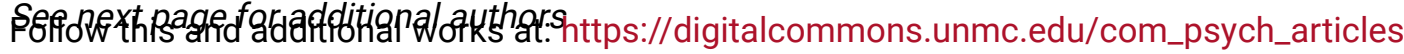 \\ Part of the Psychiatry Commons
}

\section{Recommended Citation}

Perwien, Amy R.; Kratochvil, Christopher J.; Faries, Douglas E.; Vaughan, Brigette S.; Spencer, Thomas; and Brown, Ronald T., "Atomoxetine treatment in children and adolescents with attention-deficit hyperactivity disorder: what are the long-term health-related quality-of-life outcomes?" (2006). Journal Articles:

Psychiatry. 15.

https://digitalcommons.unmc.edu/com_psych_articles/15

This Article is brought to you for free and open access by the Psychiatry at DigitalCommons@UNMC. It has been accepted for inclusion in Journal Articles: Psychiatry by an authorized administrator of DigitalCommons@UNMC. For more information, please contact digitalcommons@unmc.edu. 


\section{Authors}

Amy R. Perwien, Christopher J. Kratochvil, Douglas E. Faries, Brigette S. Vaughan, Thomas Spencer, and Ronald T. Brown

This article is available at DigitalCommons@UNMC: https://digitalcommons.unmc.edu/com_psych_articles/15 


\title{
Atomoxetine Treatment in Children and Adolescents with Attention-Deficit Hyperactivity Disorder: What Are the Long-Term Health-Related Quality-of-Life Outcomes?
} Amy R. Perwien, Ph.D.,' ${ }^{1}$ Christopher J. Kratochvil, M.D., ${ }^{2}$ Douglas E. Faries, Ph.D.,1²
Brigette S. Vaughan, B.S.N., ${ }^{2}$ Thomas Spencer, M.D., ${ }^{3}$ and Ronald T. Brown, Ph.D. ${ }^{4}$

\begin{abstract}
Objective: Numerous investigations have examined the efficacy of pharmacological treatment for attention-deficit/hyperactivity disorder (ADHD) in children. However, relatively few studies have addressed the impact of treatment on long-term subjective, psychosocial outcomes, such as health-related quality of life (HRQL). This study examines the long-term effects of pharmacological treatment with atomoxetine on HRQL in children and adolescents with ADHD.

Methods: Participants included 6- to 17-year-old children and adolescents $(n=912)$ with ADHD enrolled in a 24-month, multicenter, open-label trial of atomoxetine. Outcomes included clinician ratings of ADHD, parent ratings of ADHD, and a widely used measure of HRQL (The Child Health Questionnaire (CHQ)). Treatment response rates were calculated based on a CHQ improvement of at least 1 standard error of measurement.

Results: Significant improvements in HRQL were found following both acute and long-term treatment for psychosocial but not physical health. Of participants who completed treatment $(n$ $=312$ or $34.2 \%$ of those enrolled), $81 \%$ responded to acute treatment and $78 \%$ responded to longterm treatment. Improvements noted after acute treatment were maintained during long-term treatment with the majority of participants $(86 \%)$ continuing to respond to treatment.

Conclusions: Atomoxetine is associated with improvements in HRQL, and the improvements are generally stable over time.
\end{abstract}

\section{INTRODUCTION}

A TTENTION-DEFICIT / HYPERACTIVITY DISORDER (ADHD) is a frequently occurring childhood mental health disorder that often results in a number of functional impairments including academic difficulties (Faraone et al. 2001; Pastor and Reuben 2002), social skills deficits (Bagwell et al. 2001; Greene et al. 2001; Thurber et al. 2002), and strained family rela-

\footnotetext{
1 Outcomes Research, US Medical Division, Eli Lilly and Company, Indianapolis, Indiana.

${ }^{2}$ Department of Psychiatry, University of Nebraska Medical Center, Omaha, Nebraska.

3Department of Psychiatry, Harvard University, Boston, Massachusetts.

4Department of Public Health, Temple University, Philadelphia, Pennsylvania.

This study was funded by Eli Lilly and Company.
} 
tionships (Johnston and Mash 2001). In addition, longitudinal studies have indicated that ADHD is associated with higher rates of substance use (Weiss et al. 1985; Biederman et al. 1998; Tapert et al. 2002) as well as lower academic and occupational attainment (Mannuzza et al. 1997; Hansen et al. 1999; Barkley et al. 2002).

Given the impact of ADHD on multiple domains of functioning and the chronic nature of the disorder, ADHD recently has been viewed as a disorder that can significantly impact health-related quality of life (HRQL). HRQL is distinct from both disorder symptoms and objective functional outcomes in that it is multidimensional and subjectively examines physical, social, and psychological aspects of health (Wallander et al. 2001). In children and adolescents with ADHD, HRQL is related to disease symptomatology, but provides information beyond that obtained from traditional symptom measures (Matza et al. 2004). When comparing children with ADHD to normative data, worse HRQL in psychosocial health has been noted in children with ADHD (Landgraf et al. 1996). Consistent findings were found in a large-scale study of Australian children and adolescents $(n=3597)$, even after controlling for age, gender, family structure, and health status (Sawyer et al. 2002). These studies of HRQL in children with ADHD suggest that this is an important outcome that is not fully captured by traditional ADHD symptom measures. Not surprisingly, studies have consistently indicated that the impact of ADHD on HRQL seems to be specific to psychosocial health as opposed to physical health (Landgraf et al. 1996; Sawyer et al. 2002).

With regard to the management of ADHD and its associated symptoms, pharmacotherapy and behavior therapy are considered to be the standard of care. In fact, a number of studies have attested to the efficacy of these treatments in the management of the disorder (for reviews, see Pelham et al. 1998; Barkley 2002; Greenhill, et al. 2002; Kratochvil et al., 2003). Although numerous studies have addressed the effect of treatment on core ADHD symptoms, HRQL has not been addressed as frequently in well-controlled trials of ADHD treatments. This is despite the fact that the American Academy of
Pediatrics (AAP) has suggested that treatment outcomes should include improved functionality as well as decreased core symptomatology (American Academy of Pediatrics 2001). Some of the functional improvements areas highlighted by the AAP can be captured by psychosocial aspects of HRQL measures as has been done in double-blind, placebo-controlled trials of atomoxetine. These trials have noted that atomoxetine improved psychosocial HRQL as well as core ADHD symptoms (Michelson et al. 2001; Perwien et al. 2004).

Although well-designed long-term studies, such as the landmark Multimodal Treatment Study of Attention Deficit/Hyperactivity Disorder (MTA Cooperative Group, 1999), have noted the effectiveness of medication treatment for core ADHD symptomatology, HRQL has only recently been examined. A 9-month randomized, double-blind, placebo-controlled study of atomoxetine treatment responders found that medication was superior to placebo in improving HRQL as well as in maintaining core ADHD symptom response (Michelson et al. 2004).

In summary, research has shown both shortand long-term negative outcomes associated with childhood ADHD. Although clinical trials have consistently supported the efficacy of pharmacotherapy, less data are available on the long-term effects of these medications. Even though the psychosocial aspects of HRQL have been identified as an area of concern for children with ADHD, few studies have systematically examined the effect of treatment on HRQL, let alone response to long-term treatment. The present study builds on earlier research that supported the positive effect of acute treatment with atomoxetine on HRQL. Although core symptom response to atomoxetine was examined in this study, the primary objective of this report is to investigate the long-term outcome of atomoxetine treatment on HRQL. It was hypothesized that psychosocial HRQL would improve following 10-week acute treatment and would be maintained over a 24-month treatment phase. Given that previous research indicates poor HRQL in ADHD is specifically associated with psychosocial health, no changes in physical health following treatment were expected. 


\section{METHODS}

\section{Participants}

Children and adolescents diagnosed with ADHD who ranged in age from 6 to 17 years were enrolled in a multicenter (55 sites), openlabel trial of atomoxetine. Participants were recruited through physician referrals and by advertisement. To qualify for participation in the study, participants had to meet diagnostic and severity criteria for ADHD. Potential participants were excluded if they had a history of bipolar disorder or psychosis (including use of antipsychotic medication within 8 weeks of study enrollment), cognitive impairment (i.e., IQ <80), seizure disorder, and/or significant medical condition(s). Children also were excluded if they had a history of alcohol or drug abuse within the past 3 months. Although a history of psychotropic medication use was permitted, participants were required to be free of any psychotropic medication, including stimulant medications, and health food supplements with purported central nervous system activity for at least 5 half lives prior to study enrollment. For example, children had to be free of short-acting stimulants for at least 24 hours and long-acting stimulants for 1-2 days (Concerta ${ }^{\circledR}$ and Adderall XR $®$ for at least 17.5 hours and 48 hours, respectively).

\section{Measures}

Trained mental health providers (e.g., psychiatrists, psychologists) administered the Schedule for Affective Disorders and Schizophrenia for School-Age Children-Present/ Lifetime Version (K-SADS-PL; Ambrosini 2000) to document the presence of ADHD and to determine the subtype (combined, predominately inattentive, predominately hyperactive/impulsive). The K-SADS-PL is a semistructured psychiatric interview that allows the interviewer to incorporate data from multiple informants (i.e., parent and child) to determine diagnoses. The behavioral (ADHD, oppositional defiant disorder, conduct disorder), affective, and anxiety disorder sections were administered. The K-SADS has been found to have adequate reliability and validity (Am- brosini 2000). To assess ADHD symptom severity, the clinician-rated version of the ADHD Rating Scale (ADHD-RS; Faries et al. 2000) was completed by trained mental health providers, on the basis of an interview with the parent/ guardian, while the parents directly rated the child's behavior using the Conners' Parent Rating Scale-Revised: Short-Form (CPRS-R:S; Conners 1997). The ADHD-RS includes 18 items, each of which corresponds to a specific ADHD symptom. For entry into the study, children were required to be at least one standard deviation (SD) above the norm on the ADHD-RS for their diagnostic subtype. The CPRS-R:S is a 27item rating scale that assesses behavioral problems related to ADHD and includes the following subscales: ADHD Index, Hyperactivity, Cognitive Problems, and Oppositional.

To assess HRQL, the child's caregiver completed the Child Health Questionnaire (CHQ) (Landgraf et al. 1996). The CHQ is a generic HRQL measure that has been used in studies of children with a variety of chronic conditions including ADHD (Landgraf et al. 1996; Sawyer et al. 2002). Although a child self-report version of the CHQ exists, the parent version was selected because it is more widely researched, has normative data available, and may be used with a broad age range (children 5-18 years of age). The 50-item parent report version of the CHQ includes two summary measures (physical and psychosocial health) and 11 domain scales. Scales assessing physical functioning, pain, physical role functioning, and health perceptions address physical health. Scales measuring emotional/behavioral role functioning, behavior, mental health, self-esteem, parental time impact, parental emotional impact, and family functioning examine psychosocial health. The psychometric properties of the CHQ are described fully in the test manual (Landgraf et al. 1996) and support the internal consistency $(\alpha=0.66-0.94$ for CHQ scales), factor structure, and validity of the measure. Higher scores on the CHQ signify better HRQL.

\section{Procedures}

For each participating site, either an Institutional Review Board (IRB) at the site or a cen- 
tralized IRB approved the investigational procedures. Informed consent was obtained from each participant's parent or guardian and assent was obtained from each child. Following the informed consent process, children were evaluated to determine whether ADHD diagnostic and severity criteria were met without the presence of any exclusionary criteria. During the first 10 weeks of the study (acute phase), participants were seen on a weekly basis. During the long-term phase, visit intervals were every 3 months until either study completion (24 months) or study discontinuation. Throughout the study, children received twice-a-day dosing of atomoxetine (morning and late afternoon) with a target dose of 1.25 $\mathrm{mg} / \mathrm{kg}$ per day (mean final dose $=1.13, \mathrm{SD}=$ 0.45). The CHQ was completed at baseline, after acute treatment (10 weeks or discontinuation) and after long-term treatment (24 months or discontinuation). Clinician ratings on the ADHD-RS were obtained to examine severity of core ADHD symptoms at each visit during the acute and long-term treatment phases. Children were not permitted to begin new psychotropic medication treatments during the trial.

\section{Data analyses}

To examine baseline HRQL, $t$ scores were calculated for the ADHD sample using agebased norms provided in the CHQ user's manual (Landgraf et al. 1996). All acute-phase participants with a baseline CHQ score were included in this analysis regardless of whether or not they completed the long-term study. Due to the longitudinal nature of the study, age-based norms also were used in all subsequent analyses.

Analyses examining the response of treatment included all participants who completed long-term treatment. The analysis sample was restricted to this particular group because the primary interest of this study was long-term effects of atomoxetine treatment, and the acute effects from double-blind placebo controlled trials of atomoxetine have been described elsewhere (Michelson et al. 2001; Perwien et al. 2004). Due to the sparseness of the HRQL data collection points, the primary assessment was based on change scores between HRQL measurement points rather than employing repeated measures models. A sensitivity analysis, using repeated measures models, was also conducted. The change scores computed included: (1) Baseline to acute-phase end point and (2) acute-phase end point to the end of the long-term treatment phase. Using intent-to-treat analyses, paired $t$-tests were employed to assess whether changes were statistically different from 0 for completers (i.e., participants with 24 months of treatment). To understand better HRQL changes for participants who discontinued the investigation prematurely, secondary analyses were conducted for participants who discontinued long-term treatment ( $\geq 6$ months and $<24$ months).

To assess the clinical meaningfulness of the change scores, response rates were calculated. Although there is no gold standard approach to dichotomizing scores into response categories, participants were labeled as responders if they had an increase of at least one standard error of measurement (SEM) in their CHQ psychosocial summary score. The SEM, the standard deviation multiplied by the square root of 1 minus the reliability coefficient, represents a change above and beyond that expected by chance for an individual (Wyrwich et al. 1999). Compared to response definitions based on $t$ scores, this approach reduces problems due to participant baseline scores in or near the normative range. Based on the SEM criterion, participants were categorized into four mutually exclusive groups: (1) Acute and long-term treatment responder, (2) acute treatment responder only, (3) long-term treatment responder only, and (4) nonresponder. Because the SEM criterion simply indicates individual improvement as opposed to "normal functioning," percentages of participants within the normative range (within 1 and 1.5 standard deviations of the normed mean) also are reported.

Last, potential predictors of changes during the long-term phase of the study were assessed. ANOVA models were utilized to assess long-term changes with the following dependent variables: Investigational site, acute end point $\mathrm{CHQ}$ and ADHD-RS scores, age, gender, race, ADHD subtype, oppositional defiant disorder diagnosis, and previous stimulant use. 


\section{RESULTS}

\section{Participant characteristics}

Of the 912 participants originally enrolled in the trial, $80 \%(n=728)$ completed the 10 weeks of atomoxetine treatment ("acute participants"), 65\% $(n=591)$ completed at least 6 months of treatment ("long-term participants"), and $34 \%(n=312)$ completed the entire 24-month study ("completers"). Participant data for each phase of the study including the number of participants retained at each phase of the trial and the most common reasons for study discontinuation are presented in Fig. 1.

Table 1 presents characteristics of acute participants, long-term participants, and completers. As shown in Fig. 2, participants in the present study had baseline CHQ scores that were significantly lower (indicating worse HRQL) compared to normative data (Landgraf et al. 1996). Because the CHQ assesses the past 4 weeks and some long-term participants ( $n=$ 209) and completers $(n=132)$ were treated with stimulant medications within this timeframe, it was possible that these participants had different baseline HRQL scores compared to untreated participants due to having received treatment for ADHD. To examine this issue, participants were divided into two groups: Those taking a stimulant within 30 days prior to baseline assessment and those who had not received any stimulant medications. Because there was no significant difference between the groups in baseline psychosocial HRQL $(t=1.55, p=0.12)$, all other analyses employed the combined group.

\section{Treatment outcomes}

Table 2 summarizes HRQL and ADHD core symptom baseline and change scores for the completers. Following acute treatment with atomoxetine, significant improvements were observed on the psychosocial summary scale $(t$ statistic $=19.1, p<0.01)$ as well as all psychosocial domains (Table 2). Improvements on the psychosocial summary scale were maintained following long-term treatment $(t=0.4, p$ $=0.71$ ) and psychosocial subscale improve- ments were either maintained or slightly improved after 24 months of treatment (Table 2). Compared to the magnitude of change on the psychosocial summary scale between baseline and acute phases, the magnitude of change from acute to long-term was relatively small. However, the 24-month scores for the psychosocial summary scale and all psychosocial domains represent significant improvement over the study entry scores. The pattern of HRQL improvements was consistent with those found for core ADHD symptoms. Specifically, clinician ratings based on parent interviews (ADHD-RS Total) and direct parent reports (CPRS) of ADHD symptoms indicate significant improvement after acute treatment $(t=-39.6, p<0.01$ and $t=-33.2, p<0.01$, respectively), and these improvements were maintained or slightly improved after longterm treatment (ADHD-RS Total $t=-2.7, p=$ 0.01 and CPRS $t=-1.2, p=0.23)$. As expected, no significant improvements were found on the CHQ Physical Summary Scale or its related domain subscales after acute or long-term treatment.

As noted earlier, 279 long-term participants discontinued treatment prior to the end of the 24-month study and end point CHQ measurements were available for 182 of these cases. For these participants, psychosocial functioning after long-term treatment declined from the levels observed at the end of the acute phase (psychosocial summary score mean change $=$ $-7.7, \mathrm{SD}=14.4, t=-7.7, p<0.01)$. However, the end point scores still represent an improvement from the original baseline $(\mathrm{M}=6.0, \mathrm{SD}=$ 14.6, $t=5.5, p<0.01)$. Repeated measures analysis employing all patients was performed as a sensitivity analysis for the psychosocial summary score and showed a similar pattern as the primary assessment: A significant increase during the acute phase $(p<0.001)$ followed by stability from the acute to long-term phase $(p=0.360)$.

Assessment of predictors did not yield consistent results across analyses. Oppositional defiant disorder, past treatment with stimulants, age, prior HRQL ratings, and ADHD symptoms were all significant predictors $(p<$ 0.05 ) of long term improvement in either the analysis of completers or of all long term par- 


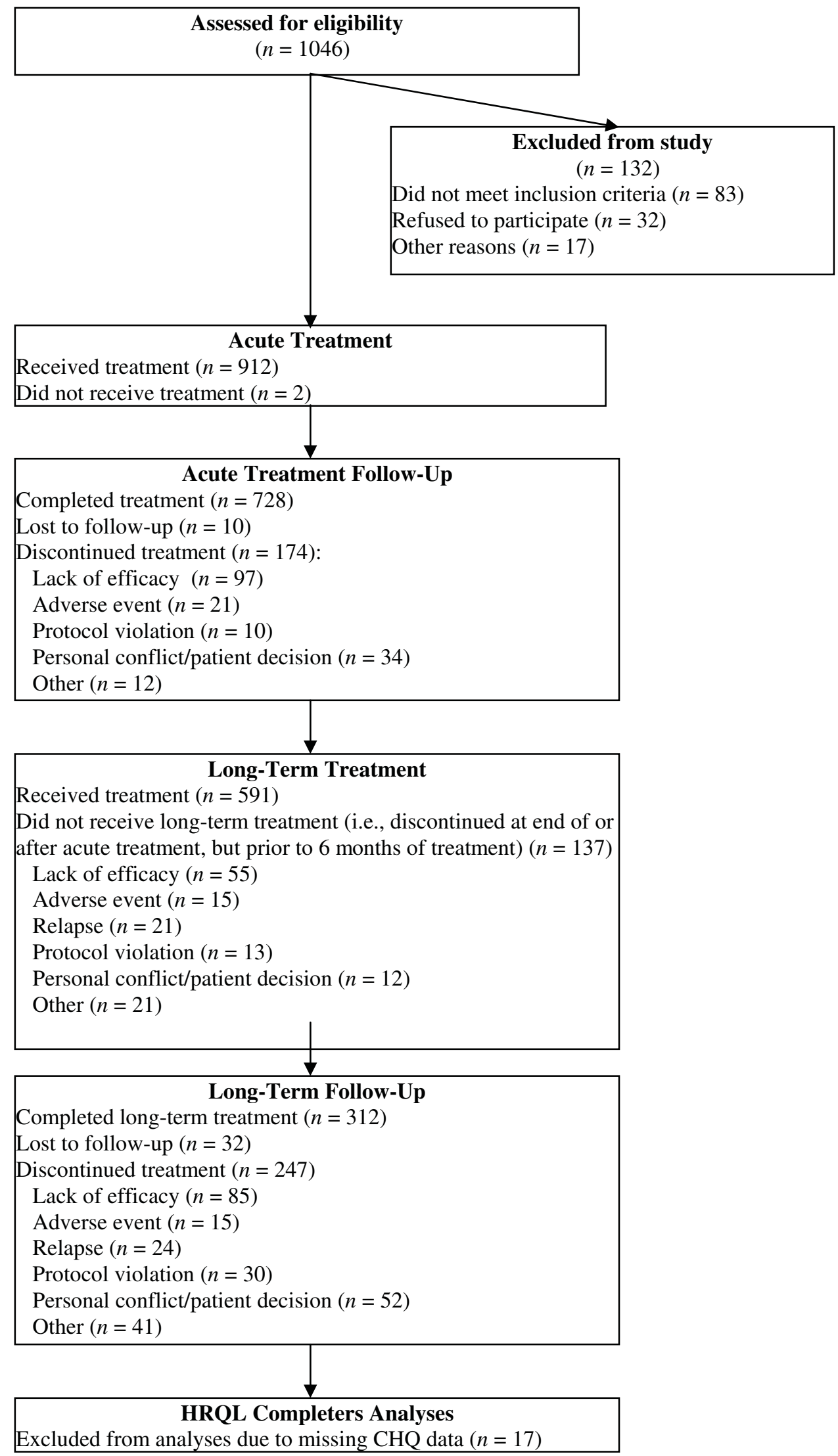

FIG. 1. Flow diagram of trial phases. $\mathrm{CHQ}=$ The Child Health Questionnaire; $\mathrm{HRQL}=$ health-related quality of life. 
Table 1. SAmple Characteristics

\begin{tabular}{lccc}
\hline & $\begin{array}{c}\text { Acute participants } \\
(\mathrm{n}=728)\end{array}$ & $\begin{array}{c}\text { Long-term participants } \\
(\mathrm{n}=591)\end{array}$ & $\begin{array}{c}\text { Completers } \\
(\mathrm{n}=312)\end{array}$ \\
\hline Age, mean (SD) & $11.1(2.8)$ & $11.1(2.7)$ & $10.9(2.6)$ \\
Male & $76.1 \%$ & $76.5 \%$ & $78.2 \%$ \\
Ethnicity & & & \\
$\quad$ White non-Hispanic & $82.8 \%$ & $82.6 \%$ & $83.7 \%$ \\
Hispanic & $7.3 \%$ & $7.6 \%$ & $8.3 \%$ \\
African American & $5.6 \% \mathrm{a} \%$ & $2.6 \% \mathrm{a}, \mathrm{b}$ \\
Other & $4.3 \%$ & $5.2 \% \mathrm{~b}$ & $5.5 \%$ \\
ADHD subtype & & $4.6 \%$ & $4.2 \%$ \\
Hyperactive/impulsive & $3.3 \%$ & $3.0 \%$ & $35.9 \%$ \\
Inattentive & $35.0 \%$ & $35.9 \%$ & $59.9 \%$ \\
Mixed & $61.7 \%$ & $61.1 \%$ & $32.1 \% \mathrm{a}, \mathrm{b}$ \\
Oppositional defiant disorder & $37.2 \% \mathrm{o}$ & $36.0 \% \mathrm{~b}$ & $76.5 \%$ \\
History of stimulant treatment & $75.6 \%$ & $75.4 \%$ & $56.9 \%$ \\
Family history of ADHD & $55.1 \%$ & $54.4 \%$ & $78.1(11.9)$ \\
ADHD-RS $t$ score (SD) & $78.8(11.4)$ & $78.7(11.4)$ & \\
\hline
\end{tabular}

Acute participants = participants who completed acute $(10$ weeks $)$ of treatment; long-term participants = participants who completed at least 6 months of atomoxetine treatment; completers = participants who completed the entire 24-month study.

$\mathrm{SD}=$ standard deviation; ADHD = attention-deficit/hyperactivity disorder; ADHD-RS = ADHD Rating Scale.

aSignificant differences $(p<0.05)$ between completers and acute participants who were not completers.

bSignificant differences $(p<0.05)$ between completers and long-term participants who were not completers.

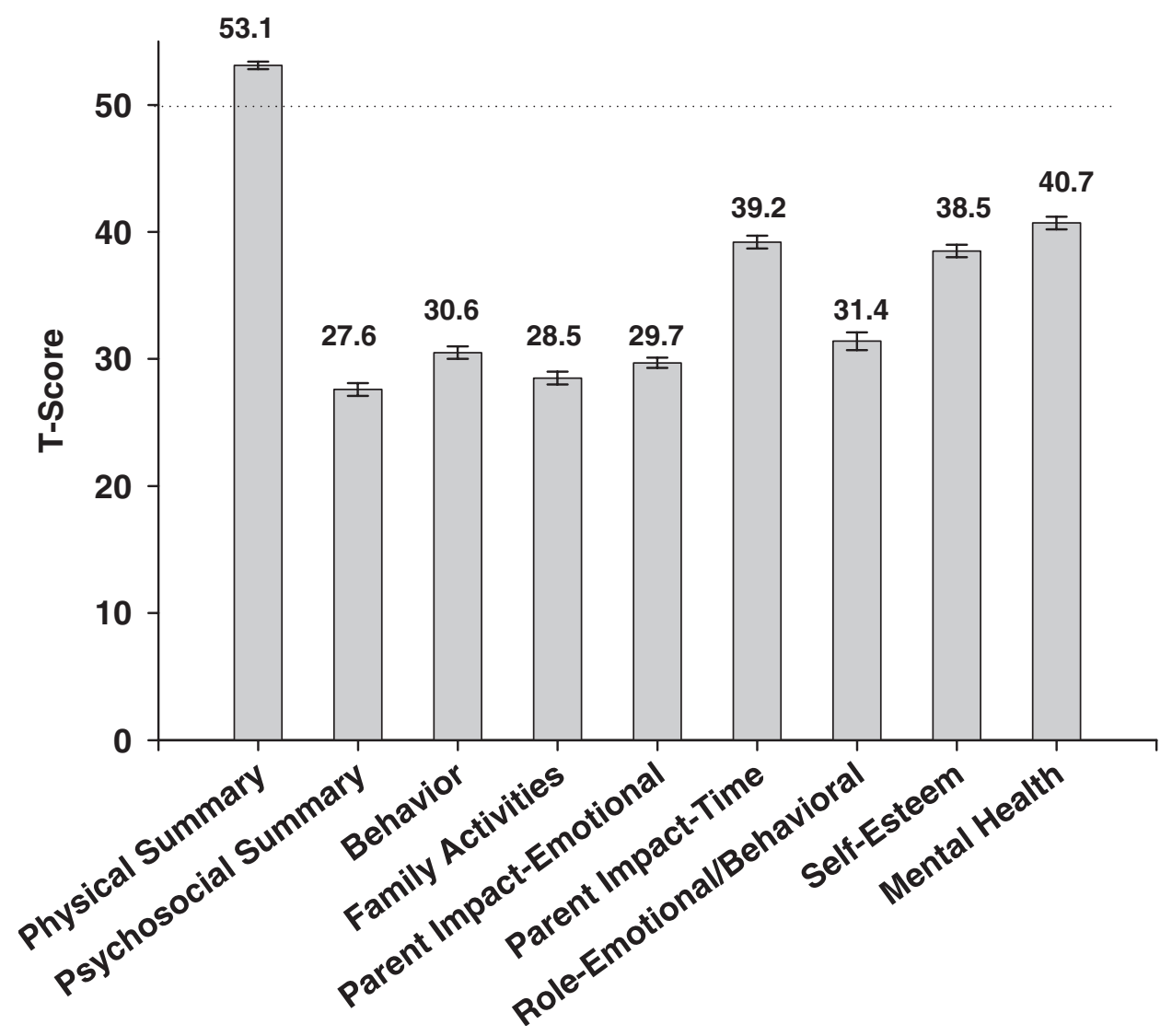

FIG. 2. Baseline Child Health Questionnaire $t$ scores for acute participants. 
Table 2. Summary of HRQL Baseline And Change SCores in ADHD for Completers

\begin{tabular}{|c|c|c|c|c|c|c|}
\hline Outcome measure & $n$ & $\begin{array}{c}\text { Baseline } \\
\text { mean (SD) }\end{array}$ & $\begin{array}{l}\text { Baseline to acute } \\
\text { change } \\
\text { mean (SD) }\end{array}$ & $p$ & $\begin{array}{l}\text { cute to long-term } \\
\text { change } \\
\text { mean (SD) }\end{array}$ & $p$ \\
\hline \multicolumn{7}{|l|}{ CHQ $t$ scores (age-based) } \\
\hline Physical summary & 281 & $53.2(7.9)$ & $-0.8(8.6)$ & 0.117 & $0.1(8.1)$ & 0.769 \\
\hline Psychosocial summary & 281 & $29.0(13.1)$ & $15.1(13.3)$ & $<0.001$ & $0.2(11.2)$ & 0.709 \\
\hline Behavior & 294 & $32.5(12.3)$ & $13.6(11.1)$ & $<0.001$ & $0.1(9.4)$ & 0.813 \\
\hline Family activities & 294 & $29.9(14.1)$ & $12.2(13.4)$ & $<0.001$ & $0.6(11.5)$ & 0.375 \\
\hline Parental impact-emotional & 292 & $30.6(10.8)$ & $10.8(13.4)$ & $<0.001$ & $2.5(14.0)$ & 0.003 \\
\hline Parental impact-time & 294 & 39.4 (11.6) & $8.0(12.5)$ & $<0.001$ & $1.2(11.4)$ & 0.067 \\
\hline Role-emotional/behavioral & 295 & $32.1(19.3)$ & $14.2(21.0)$ & $<0.001$ & $-0.4(15.2)$ & 0.682 \\
\hline Self esteem & 292 & $39.6(11.9)$ & $7.9(12.1)$ & $<0.001$ & $-0.8(11.8)$ & 0.260 \\
\hline Mental health & 293 & $42.4(13.6)$ & $7.5(14.0)$ & $<0.001$ & $-0.7(11.0)$ & 0.249 \\
\hline
\end{tabular}

All patients with a baseline, acute treatment, and 24-month, long-term treatment score were included in the analysis.

$\mathrm{SD}=$ standard deviation; $\mathrm{CHQ}=$ Child Health Questionnaire; $\mathrm{HRQL}=$ health-related quality of life; $\mathrm{ADHD}=$ at-

tention-deficit/hyperactivity disorder.

ticipants. For the completers, lack of prior stimulant use, older age, less severe ADHD symptoms at acute treatment end point, and worse HRQL at acute treatment end point were predictive of greater HRQL improvements. In examining all long-term participants, only worse HRQL following acute treatment and the lack of oppositional defiant disorder were predictive of more improved HRQL.

\section{Response rates}

Using the response definition of an improvement in the psychosocial summary score of at least one SEM, the majority of completers were responders at the end of long-term treatment (Table 3). A total of $81.1 \%(n=228)$ of the completers were responders at the end of the acute phase and $78.3 \%(n=220)$ were responders after 24 months of treatment. Of the completers who responded after acute treatment, $86 \%(n=196)$ continued to meet response criteria at the end of the study. Consistent with response rate data for the completers, the majority of long-term participants met response criteria at their final measurement (Table 3). Of the long-term participants who were responders after the acute phase, $78.4 \%(n=283)$ continued to meet response criteria at end point. Using $t$ scores to examine response rates, the majority of completers were responders following long-term treatment. Specifi- cally, $67.3 \%(n=189)$ and $80.1 \%(n=225)$ of these participants were within the normative range using 1.0 and $1.5 \mathrm{SD}$ range definitions, respectively.

TAble 3. Response RAtes for Long-Term Participants AND COMPLETERS

\begin{tabular}{lcc}
\hline & $\begin{array}{c}\text { Long-term } \\
\text { participants } \\
(\mathrm{n}=456)\end{array}$ & $\begin{array}{c}\text { Completers } \\
(\mathrm{n}=281)\end{array}$ \\
\hline $\begin{array}{c}\text { Acute and long-term } \\
\text { treatment responder }\end{array}$ & $62 \%$ & $70 \%$ \\
$\begin{array}{c}\text { Acute treatment only } \\
\text { responder }\end{array}$ & $17 \%$ & $11 \%$ \\
$\begin{array}{c}\text { Long-term treatment only } \\
\text { responder } \\
\text { Nonresponder }\end{array}$ & $8 \%$ & $9 \%$ \\
\hline
\end{tabular}

Long-term participants $=$ participants completing at least 6 months of treatment; completers $=$ participants completing the entire 24-month study.

Response definition is based on the following criterion: a baseline to end point increase of at least one standard error of measurement (SEM) in CHQ psychosocial summary score.

Acute and long-term treatment responder $=$ participant responded after both the acute (10 weeks of treatment) and long-term treatment phases; acute treatment only responder = participant responded after acute treatment but not after long-term treatment; long-term treatment only responder $=$ participant responded after long-term treatment but not after acute treatment; nonresponder $=$ participant did not respond after acute or long-term treatment.

$\mathrm{CHQ}=$ Child Health Questionnaire 


\section{DISCUSSION}

At baseline, participants in this study were experiencing significantly worse HRQL in areas of psychosocial health compared to normative data. These findings are consistent with other investigations (Landgraf et al. 1996; Sawyer et al. 2002), and indicate that HRQL is an area of concern for children with ADHD. In addition, research indicates that HRQL is an outcome that is not fully captured by the measurement of core ADHD symptomatology (Matza et al. 2004). Therefore, the assessment of HRQL should be viewed as a complementary procedure because HRQL represents a domain beyond traditional health status (e.g., ADHD core symptoms) by examining the subjective impact of a disorder. In fact, the AAP also has recognized the importance of evaluating treatment across outcome domains, including behavioral, academic, and psychosocial functioning (American Academy of Pediatrics 2001). This type of multidimensional evaluation is likely to capture a full picture of treatment effectiveness including meaningful HRQL outcomes such as social functioning, family relationships, and psychological functioning.

In terms of outcomes of treatment with atomoxetine, findings from this study add to previously published data from acute, doubleblind placebo controlled clinical trials. These trials, which have examined treatment effects over relatively short periods of time (i.e., 8-10 weeks), support the efficacy of atomoxetine on core ADHD symptoms as well as HRQL outcomes (Michelson et al. 2001; Perwien et al. 2004). The present study further supports earlier results by indicating that the HRQL improvements observed after acute treatment with atomoxetine were generally maintained. These data suggest that improvements found after acute treatment were durable rather than transitory. This pattern is consistent with changes found for core ADHD symptoms. Finally, consistent with the symptoms of the disorder and data previously reported by Perwien et al. (2004), HRQL improvements were specific to areas of psychosocial rather than physical health.
Although some improvement was observed from acute to long-term end point related to the impact of ADHD on parents emotional adjustment, the majority of psychosocial HRQL domains remained stable. One possibility is that the failure to document further improvement may be due to ceiling effects and/or response shift. In a previous study (Perwien et al. 2004), less psychosocial impairment at baseline was associated with less improvement following acute treatment with atomoxetine. Thus, participants who evidenced better baseline HRQL scores were more limited in the amount of improvement they could experience compared to participants who had worse baseline scores. Therefore, it is possible that participants in the present study who had high HRQL at the beginning of the study had less opportunity to improve significantly beyond their acute scores. Response shift offers another explanation as to why there were not further improvements from acute to long-term treatment for the majority of psychosocial health scales. It has been defined as, "a change in the meaning of one's self-evaluation of quality of life (QOL) as a result of changes in internal standards, values, and the conceptualization of QOL" (Sprangers and Schwartz 2000, p. 14) following a change in health status. Parents in this study may have experienced response shift because their children's health status (i.e., ADHD core symptoms) improved, resulting in a change in their internal standard of HRQL measurement (recalibration). If the recalibration were more stringent, it would be more difficult to demonstrate improvement over the course of long-term treatment.

The findings of this study should be interpreted with some caution due to the openlabel study design and the attrition rate. Despite the open-label design, however, the acute findings were consistent with doubleblind placebo controlled trials, suggesting that the design did not unduly bias the results. Furthermore, it could be hypothesized that if the influence of receiving a medication overly influenced perceived HRQL, treatment effects might be less likely to be maintained because the novelty of the treatment would decrease over time. Attrition rates are generally a chal- 
lenge for long-term treatment studies, and the present investigation is no exception. In this study, only $52.8 \%$ of participants who began long-term treatment completed the full 24month study and only $34.2 \%$ of the patients that began acute treatment finished the full 24months of the study. It is possible that participants who completed the study were the most receptive to treatment with atomoxetine. In fact, those who remained in the study for the full 24-month duration had greater improvements on HRQL compared to those who discontinued participation prematurely.

Several unanswered issues remain and are of potential interest for future investigation. For example, whether HRQL improvements plateau or fluctuate following long-term treatment cannot be determined from this study because of the limited measurement points (i.e., baseline, acute end point, long-term end point). Future studies should include children's perceptions of their own HRQL. Including both parent and child informants would not only provide a more complete picture of the effect of treatment on HRQL, but would also give insight into the consistency between parent and child reports for children with ADHD. In fact, some studies indicate that parents and children have different perceptions of children's HRQL (Vogels et al. 1998; Sawyer et al. 1999; Levi and Drotar 1999).

Another area for future investigation is the effect of multimodal treatment. Although the MTA study (MTA Cooperative Group 1999) did not indicate superior effects for the combined treatment arm (medication plus behavior therapy) compared to optimally administered medication alone, it is possible that some of the HRQL outcomes may be amenable to combination treatments that include a psychotherapeutic component. In addition, additional study is needed to assess potential predictors of improvement further in HRQL.

Finally, atomoxetine appears to be a particularly attractive medication intervention because it does not have some of the potential limitations of stimulant medications (Kratochvil et al. 2003) and appears to provide continuous symptom improvement (Kelsey et al. 2004). Although this study cannot address whether or not these characteristics of atomox- etine have a positive effect on HRQL, it is possible that these factors play a role in improving HRQL. For example, continuous symptom relief may allow for a child to have improved interactions with family members which may, in turn, enhance family functioning aspects of HRQL.

Notwithstanding the aforementioned limitations and examined in conjunction with previous findings (Michelson et al. 2001; Perwien et al. 2004), this study supports the positive response to atomoxetine treatment on HRQL in children and adolescents. As these data indicate, improved HRQL is present following acute treatment and is maintained over longterm treatment. Although medications for chronic conditions, such as ADHD, are developed to improve specific symptoms and evaluated on disease-related health status measures (e.g., core ADHD symptoms), successful treatment may be better indicated by improvement in both health status and functional outcomes. This may be especially important in chronic conditions that have been documented to be associated with relatively poor HRQL. The present investigation provides a model for evaluating ADHD treatment on domains of functioning not previously documented in other studies.

\section{DISCLOSURE}

At the time this research was conducted, Dr. Perwien was an employee of Eli Lilly and Company. Dr. Faries is currently an employee and stockholder in Eli Lilly and Company. Dr. Kratochvil is a paid consultant for Eli Lilly and Company, GlaxoSmithKline, Forest, Cephalon, Novartis, McNeil, Organon USA, AstraZeneca, and Pfizer. Dr. Spencer is a paid consultant for Eli Lilly and Company, McNeil, Novartis, Shire, Johnson \& Johnson, and Janssen. Dr. Brown is a paid consultant for Shire. Ms. Vaughan has no conflict of interest or financial ties to disclose.

\section{ACKNOWLEDGMENTS}

This research was funded by Eli Lilly and Company. The authors gratefully acknowl- 
edge the contributions of all the investigators and families involved in the clinical trials.

\section{REFERENCES}

Ambrosini PJ: Historical development and present status of the Schedule for Affective Disorders and Schizophrenia for school-age children (K-SADS). J Am Acad Child Adolesc Psychiatry 39:49-58, 2000.

American Academy of Pediatrics Committee on Quality Improvement, Subcommittee on Attention-Deficit/Hyperactivity Disorder: Clinical practice guideline: Treatment of the school-age child with attention-deficit/hyperactivity disorder. Pediatrics 108:1033-1044, 2001.

Bagwell CL, Molina BS Pelham WE, Hoza B: Attention-deficit hyperactivity disorder and problems in peer relations: Predictions from childhood to adolescence. J Am Acad Child Adolesc Psychiatry 40:1285-1292, 2001.

Barkley RA: Psychosocial treatment for attentiondeficit/hyperactivity disorder in children. J Clin Psychiatry 63:36-43, 2002.

Barkley RA, Fischer M, Smallish L Fletcher, K: The persistence of attention-deficit/hyperactivity disorder into young adulthood as a function of reporting source and definition of disorder. J Abnorm Psychol 111:279-289, 2002.

Biederman J, Wilens T, Mick E, Faraone SV, Spencer $\mathrm{T}$ : Does attention-deficit hyperactivity disorder impact the developmental course of drug and alcohol abuse and dependence? Biol Psychiatry, 44:269-273, 1998.

Conners CK: Conners' Rating Scales: Revised Technical Manual. North Towanda, NY, Multi-Health Systems, 1997.

DuPaul GJ, Power TJ, Anastopoulos AD, Reid R: ADHD Rating Scale-IV: Checklists, Norms and Clinical Interpretations. New York, The Guilford Press, 1998.

Faraone SV, Biederman J, Monuteaux MC, Doyle AE, Seidman, LJ: A psychometric measure of learning disability predicts educational failure four years later in boys with attention-deficit/hyperactivity disorder. J Atten Disord 4:220-230, 2001.

Faries DE, Yalcin I, Harder D, Heiligenstein JH: Validation of the ADHD Rating Scale as a clinician administered and scored instrument. J Atten Disord, 5:107-115, 2000.

Greene RW, Biederman J, Faraone SV, Monuteaux MC, Mick E, DuPre EP, Fine CS, Goring JL: Social impairment in girls with ADHD: Patterns, gender comparisons, and correlates. J Am Acad Child Adolesc Psychiatry, 40:704-710, 2001.

Greenhill L, Pliszka S, Dulcan MK, Bernet W, Arnold V, Beitchman J, Benson RS, Bukstein O, Kinlan J, McCellan J, Rue D, Shaw JA, Stock S,
American Academy of Child and Adolescent Psychiatry: Practice parameter for the use of stimulant medications in the treatment of children, adolescents, and adults. J Am Acad Child Adolesc Psychiatry 41:26S-49S, 2002.

Hansen C, Weiss D, Last CG: ADHD boys in young adulthood: psychosocial adjustment. J Am Acad Child Adolesc Psychiatry 38:165-171, 1999.

Hechtman L, Abikoff H, Klein RG, Weiss G, Respitz C, Kouri J, Blum C, Greenfield B: Academic achievement and emotional status of children with ADHD treated with long-term methylphenidate and multimodal psychosocial treatment. J Am Acad Child Adolesc Psychiatry 43: 812-819, 2004.

Johnston C, Mash, EJ: Families of children with attention-deficit/hyperactivity disorder: Review and recommendations for future research. Clin Child Fam Psychol Rev 4:183-207, 2001.

Kelsey DK, Sumner CR, Casat CD, Coury DL, Quintana H, Saylor KE, Sutton VK, Gonzales J, Malcolm SK, Schuh KJ, Allen AJ: Once-daily atomoxetine treatment for children with attention-deficit/hyperactivity disorder, including an assessment of evening and morning behavior: A double-blind, placebo-controlled trial. Pediatrics 114:1-8, 2004.

Kratochvil CJ, Vaughan BS, Harrington MJ, Burke WJ: Atomoxetine: A selective noradrenaline reuptake inhibitor for the treatment of attentiondeficit/hyperactivity disorder. Expert Opin 4: 1165-1174, 2003.

Landgraf J, Abetz L, Ware J: Child Health Questionnaire (CHQ): A User's Manual. Boston, Integrated Therapeutics Group, 1996.

Levi RB, Drotar D: Health-related quality of life in childhood cancer: Discrepancy in parent-child report. Int J Cancer S12:58-64, 1999.

Mannuzza S, Klein RG, Bessler A, Malloy P, Hynes ME: Educational and occupational outcome of hyperactive boys grown up. J Am Acad Child Adolesc Psychiatry 36:1222-1227, 1997.

Matza LS, Rentz AM, Secnik K, Swensen AM, Revicki DA, Michelson D, Spencer T, Newcorn JH, Kratochvil CJ: The link between health related quality of life and clinical symptoms among children with attention-deficit hyperactivity disorder. J Dev Behav Pediatr 25:166-174, 2004.

Michelson D, Buitelaar JK, Danckaerts M, Gillberg C, Spencer TJ, Zuddas A, Faries DE, Zhang S, Biederman J: Relapse prevention in pediatric patients with ADHD treated with atomoxetine: a randomized, double-blind, placebo-controlled study. J Am Acad Child Adolesc Psychiatry 43:896-904, 2004. Michelson D, Faries D, Wernicke J, Kelsey D, Kendrick K, Sallee FR, Spencer T: Atomoxetine in the treatment of children and adolescents with attention-deficit/hyperactivity disorder: A randomized, placebo-controlled, dose-response study. Pediatrics 108:e83, 2001. 
MTA Cooperative Group: A 14-month randomized clinical trial of treatment strategies for attentiondeficit/hyperactivity disorder. Arch Gen Psychiatry 56:1073-1086,1999.

Pastor PN, Reuben CA: Attention deficit disorder and learning disability: United States, 1997-1998. Vital Health Statistics 10:1-11, 2002.

Pelham WE, Wheeler T, Chronis A: Empirically supported psychosoial treatments for attention deficit hyperactivity disorder. J Clin Child Psychol 27:190-205, 1998.

Perwien AR, Faries DE, Kratochvil CJ, Sumner CR, Kelsey DK, Allen AJ: Improvement in health-related quality of life in children with ADHD: An analysis of placebo controlled studies of atomoxetine. J Dev Behav Pediatr 25:264-271, 2004

Sawyer M, Antoniou G, Toogood I, Rice M: A comparison of parent and adolescent reports describing the health-related quality of life of adolescents treated for cancer. Int $\mathrm{J}$ Cancer S12:39-45, 1999.

Sawyer MG, Whaites L, Rey JM, Hazell PL, Graetz B, Baghurst P: Health-related quality of life of children and adolescents with mental disorders. J Am Acad Child Adolesc Psychiatry 41:530-537, 2002.

Sprangers MAG, Schwartz CE: Integrating response shift into health-related quality-of-life research: a theoretical model. In: Adaptation to Changing Health: Response Shift in Quality-ofLife Research. Edited by Sprangers MAG, Schwartz CE. Washington, DC, American Psychological Association, 2000, pp 11-23.

Tapert SF, Baratta MV, Abrantes AM, Brown S: Attention dysfunction predicts substance involve- ment in community youths. J Am Acad Child Adolesc Psychiatry 41:680-686, 2002.

Thurber JR, Heller TL, Hinshaw SP: The social behaviors and peer expectation of girls with attention deficit hyperactivity disorder and comparison girls. J Clin Child Adolesc Psychol 31:443-452, 2002.

Vogels T, Verrips GH, Verloove-Vanhorick SP, Fekkes M, Kamphuis RP, Koopman HM, Theunissen NC, Wit JM: Measuring health-related quality of life in children: The development of the TACQOL parent form. Qual Life Res 7:457-465, 1998. Wallander JL, Schmitt M, Koot HM: Quality of life measurement in children and adolescents: Issues, instruments, and applications. J Clin Psychol 57:571-585, 2001.

Weiss G, Hechtman L, Milroy T, Perlman T: Psychiatric status of hyperactives as adults: A controlled prospective 15-year follow-up of 63 hyperactive children. J Am Acad Child Adolesc Psychiatry 24:211-220, 1985.

Wyrwich KW, Tierney WM, Wolinsky FD: Further evidence supporting an SEM-based criterion for identifying meaningful intra-individual changes in health-related quality of life. J Clin Epidemiol 52:861-873, 1999.

Address reprint requests to: Douglas Faries, Ph.D. Lilly Corporate Center Indianapolis, IN 46285

E-mail: faries_douglas_e@lilly.com 


\section{This article has been cited by:}

1. Ralf W. Dittmann, Tobias Banaschewski, Alexander Schacht, Peter M. Wehmeier. 2014. Findings from the observational COMPLY study in children and adolescents with ADHD: core symptoms, ADHD-related difficulties, and patients' emotional expression during psychostimulant or nonstimulant ADHD treatment. ADHD Attention Deficit and Hyperactivity Disorders . [CrossRef]

2. Renata Rizzo, Mariangela Gulisano, Paola V. Calì, Paolo Curatolo. 2013. Tourette Syndrome and comorbid ADHD: Current pharmacological treatment options. European Journal of Paediatric Neurology 17:5, 421-428. [CrossRef]

3. Cristiano Termine, Claudia Selvini, Giorgio Rossi, Umberto BalottinEmerging Treatment Strategies in Tourette Syndrome 112, 445-480. [CrossRef]

4. Aviv Weinstein, Abraham Weizman. 2012. Emerging Association Between Addictive Gaming and Attention-Deficit/ Hyperactivity Disorder. Current Psychiatry Reports 14:5, 590-597. [CrossRef]

5. Rongwang Yang, Shujiong Mao, Rong Li, Zhengyan Zhao. 2012. The Need to Develop More Sensitive Tools to Accurately Detect Clinical Response to Treatment in ADHD. CNS Drugs 26:2, 185-186. [CrossRef]

6. David Coghill. 2011. Escalas y cuestionarios pragmáticos en psicofarmacología pediátrica: ¿estamos haciendo lo correcto?. Psiquiatría Biológica . [CrossRef]

7. Alexander Schacht, Rodrigo Escobar, Thomas Wagner, Peter M. Wehmeier. 2011. Psychometric properties of the quality of life scale Child Health and Illness Profile-Child Edition in a combined analysis of five atomoxetine trials. ADHD Attention Deficit and Hyperactivity Disorders . [CrossRef]

8. Yu-Shu Huang, Ming-Horng Tsai. 2011. Long-Term Outcomes with Medications for Attention-Deficit Hyperactivity Disorder. CNS Drugs 25:7, 539-554. [CrossRef]

9. Peter M. Wehmeier, Alexander Schacht, Ralf W. Dittmann, Karin Helsberg, Christian Schneider-Fresenius, Martin Lehmann, Monika Bullinger, Ulrike Ravens-Sieberer. 2011. Effect of atomoxetine on quality of life and family burden: results from a randomized, placebo-controlled, double-blind study in children and adolescents with ADHD and comorbid oppositional defiant or conduct disorder. Quality of Life Research 20:5, 691-702. [CrossRef]

10. Robert L. Findling, Ann C. Childress, Andrew J. Cutler, Maria Gasior, Mohamed Hamdani, M. Celeste Ferreira-Cornwell, Liza Squires. 2011. Efficacy and Safety of Lisdexamfetamine Dimesylate in Adolescents With Attention-Deficit/Hyperactivity Disorder. Journal of the American Academy of Child \& Adolescent Psychiatry 50:4, 395-405. [CrossRef]

11. Jeffery R. Wickens, Brian I. Hyland, Gail Tripp. 2011. Animal models to guide clinical drug development in ADHD: Lost in translation?. British Journal of Pharmacology no-no. [CrossRef]

12. N. N. Zavadenko, T. V. Lebedeva, O. V. Schasnaya, A. N. Zavadenko, O. M. Zlobina, N. A. Semenova. 2011. Attention Deficit Hyperactivity Syndrome: The Role of Parent and Teacher Questionnaires in Assessing the Social and Psychological Adaptation of Patients. Neuroscience and Behavioral Physiology 41:1, 52-56. [CrossRef]

13. David Coghill. 2010. Pragmatic measures in paediatric psychopharmacology - Are we getting it right?. European Neuropsychopharmacology . [CrossRef]

14. Thomas W. Frazier, Margaret Weiss, Paul Hodgkins, Michael J. Manos, Jeanne M. Landgraf, Christopher Gibbins. 2010. Time Course and Predictors of Health-Related Quality of Life Improvement and Medication Satisfaction in Children Diagnosed with Attention-Deficit/Hyperactivity Disorder Treated with the Methylphenidate Transdermal System. Journal of Child and Adolescent Psychopharmacology 20:5, 355-364. [Abstract] [Full Text HTML] [Full Text PDF] [Full Text PDF with Links]

15. David Coghill. 2010. The Impact of Medications on Quality of Life in Attention-Deficit Hyperactivity Disorder. CNS Drugs 24:10, 843-866. [CrossRef]

16. Rodrigo Escobar, Alexander Schacht, Peter M. Wehmeier, Thomas Wagner. 2010. Quality of Life and Attention-Deficit/ Hyperactivity Disorder Core Symptoms. Journal of Clinical Psychopharmacology 30:2, 145-151. [CrossRef]

17. Peter M. Wehmeier, Alexander Schacht, Russell A. Barkley. 2010. Social and Emotional Impairment in Children and Adolescents with ADHD and the Impact on Quality of Life. Journal of Adolescent Health 46:3, 209-217. [CrossRef]

18. Marina Danckaerts, Edmund J. S. Sonuga-Barke, Tobias Banaschewski, Jan Buitelaar, Manfred Döpfner, Chris Hollis, Paramala Santosh, Aribert Rothenberger, Joseph Sergeant, Hans-Christoph Steinhausen, Eric Taylor, Alessandro Zuddas, David Coghill. 2010. The quality of life of children with attention deficit/hyperactivity disorder: a systematic review. European Child \& Adolescent Psychiatry 19:2, 83-105. [CrossRef]

19. Michelle Stewart, Melissa P. DelBello, Mark Versavel, David Keller. 2009. Psychosocial Functioning and Health-Related Quality of Life in Children and Adolescents Treated with Open-Label Ziprasidone for Bipolar Mania, Schizophrenia, or Schizoaffective 
Disorder. Journal of Child and Adolescent Psychopharmacology 19:6, 635-640. [Abstract] [Full Text HTML] [Full Text PDF] [Full Text PDF with Links]

20. Ralf W. Dittmann, Peter M. Wehmeier, Alexander Schacht, Martin Lehmann, Gerd Lehmkuhl. 2009. Self-esteem in adolescent patients with attention-deficit/hyperactivity disorder during open-label atomoxetine treatment: psychometric evaluation of the Rosenberg Self-Esteem Scale and clinical findings. ADHD Attention Deficit and Hyperactivity Disorders 1:2, 187-200. [CrossRef]

21. Pär Svanborg, Gunilla Thernlund, Per A. Gustafsson, Bruno Hägglöf, Alexander Schacht, Björn Kadesjö. 2009. Atomoxetine improves patient and family coping in attention deficit/hyperactivity disorder: a randomized, double-blind, placebo-controlled study in Swedish children and adolescents. European Child \& Adolescent Psychiatry 18:12, 725-735. [CrossRef]

22. Michael Manos, Thomas W. Frazier, Jeanne M. Landgraf, Margaret Weiss, Paul Hodgkins. 2009. HRQL and medication satisfaction in children with ADHD treated with the methylphenidate transdermal system. Current Medical Research and Opinion 25:12, 3001-3010. [CrossRef]

23. Grazia Dell'Agnello, Dino Maschietto, Carmela Bravaccio, Filippo Calamoneri, Gabriele Masi, Paolo Curatolo, Dante Besana, Francesca Mancini, Andrea Rossi, Lynne Poole, Rodrigo Escobar, Alessandro Zuddas. 2009. Atomoxetine hydrochloride in the treatment of children and adolescents with attention-deficit/hyperactivity disorder and comorbid oppositional defiant disorder: A placebo-controlled Italian study. European Neuropsychopharmacology 19:11, 822-834. [CrossRef]

24. David Coghill, Marina Danckaerts, Edmund Sonuga-Barke, Joseph Sergeant. 2009. Practitioner Review: Quality of life in child mental health - conceptual challenges and practical choices. Journal of Child Psychology and Psychiatry 50:5, 544-561. [CrossRef]

25. JoAnn Elizabeth Leavey, Monica Flexhaug, Tom Ehmann. 2008. Review of the literature regarding early intervention for children and adolescents aged 0-15 experiencing a first-episode psychiatric disturbance. Early Intervention in Psychiatry 2:4, 212-224. [CrossRef]

26. Xiao-Hua Ji, Jin-Zhao Ji, Hui Zhang, Bao-Ming Li. 2008. Stimulation of a2-Adrenoceptors Suppresses Excitatory Synaptic Transmission in the Medial Prefrontal Cortex of Rat. Neuropsychopharmacology 33:9, 2263-2271. [CrossRef]

27. Page A.W. Anderson, Lynn A. Sleeper, Lynn Mahony, Steven D. Colan, Andrew M. Atz, Roger E. Breitbart, Welton M. Gersony, Dianne Gallagher, Tal Geva, Renee Margossian, Brian W. McCrindle, Stephen Paridon, Marcy Schwartz, Mario Stylianou, Richard V. Williams, Bernard J. Clark. 2008. Contemporary Outcomes After the Fontan Procedure. Journal of the American College of Cardiology 52:2, 85-98. [CrossRef]

28. Richard H. Gilchrist, L. Eugene Arnold. 2008. Long-Term Efficacy of ADHD. Pediatric Annals 37:1, 46-51. [CrossRef]

29. Richard H. Gilchrist, L. Eugene Arnold. 2008. Long-Term Efficacy of ADHD. Psychiatric Annals 38:1, 52-57. [CrossRef]

30. Peter M. Wehmeier, Ralf W. Dittmann, Alexander Schacht, Anette Minarzyk, Martin Lehmann, Kathrin Sevecke, Gerd Lehmkuhl. 2007. Effectiveness of Atomoxetine and Quality of Life in Children with Attention-Deficit/Hyperactivity Disorder as Perceived by Patients, Parents, and Physicians in an Open-Label Study. Journal of Child and Adolescent Psychopharmacology 17:6, 813-830. [Abstract] [Full Text PDF] [Full Text PDF with Links]

31. 2007. Prescriptions Into Practice. Child and Adolescent Psychopharmacology News 12:5, 4-10. [CrossRef]

32. Katharina Manassis. 2007. When attention-deficit/hyperactivity disorder co-occurs with anxiety disorders: effects on treatment. Expert Review of Neurotherapeutics 7:8, 981-988. [CrossRef] 